\title{
The Effect of Plasma Treatment on the Release Kinetics of a Chemotherapy Drug from Biodegradable Polyester Films and Polyester-Urethane Films
}

Petr Stloukal $^{1,}$, Igor Novák ${ }^{2}$, Matej Mičušík ${ }^{2}$, Michal Procházka $^{2}$, Pavel Kucharczyk $^{1}$, Ivan Chodák ${ }^{2}$, Marian Lehocký ${ }^{1}$, Vladimír Sedlařík ${ }^{1}$

${ }^{1}$ Centre of Polymer Systems, University Institute, Tomas Bata University in Zlín, tř. T. Bati, Zlín, Czech Republic, ${ }^{2}$ Polymer Institute, Slovak Academy of Sciences, Dubravská cesta, Bratislava, Slovak Republic

Corresponding author: Petr Stloukal, E-mail: StloukalP@seznam.cz

\begin{abstract}
Investigation was made into the effect of plasma treatment on the release kinetics of the drug Temozolomide (TMZ) from thin, biodegradable polyester films, comprising polylactic acid (PLA) and polyester urethane (PEU). The authors utilized two systems to achieve this, the first being diffuse coplanar surface barrier discharge, applying air as the gaseous medium, while the other involved capacitively coupled radio-frequency discharge plasma in an argon atmosphere with hexamethyldisiloxane. Results showed that both forms of plasma treatment positively reduced the undesirable burst effect and benefited the release rate of the TMZ. The hydrolytic degradability of the materials was slightly enhanced following hydrophilization, whereas the same diminished after hydrophobization had taken place. This was especially true for PLA due to modification of its wettability.
\end{abstract}

\section{GRAPHICAL ABSTRACT:}



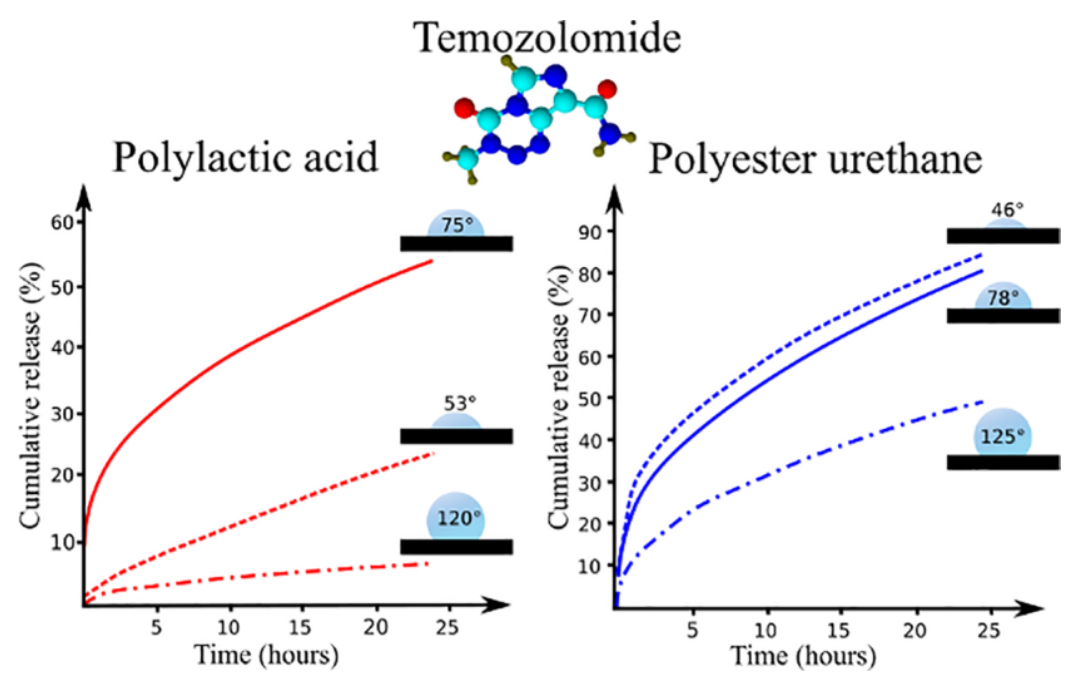

KEYWORDS: Biodegradable materials; capacitively coupled radio-frequency plasma; control release; diffuse coplanar surface barrier discharge, plasma treatments.

\section{INTRODUCTION}

Aliphatic polyester-based polymers have attracted considerable attention as promising forms of biopolymer for control release devices, due to their biocompatibility, low toxicity and feasible biodegradability. ${ }^{[1,2]}$ One notable application for biodegradable polyesters is the controlled delivery of therapeutic agents. For this purpose the aforementioned advantages would be augmented by additional benefits, such as enhanced stability of bioactive agents and contributive therapeutic treatment. However, such systems often possess certain shortcomings, e.g. the possibility of overdose during initial administration and anomalous changes in release rates. ${ }^{[3,4]}$ It is well-known that the high, initial burst release of the given drug might cause a concentration exceeding the toxicity limit in the human body ${ }^{[5]}$ Additionally, in many cases it is greatly desirable to deliver drugs at a constant zero-order release rate, so as to suit the requirements of administration. $^{[6,7]}$ 
To this end, the plasma treatment of polymer surfaces has emerged as an effective tool for tuning the release rate and kinetics of drugs. ${ }^{[8-11]}$ The advantage of plasma treatment techniques is that they allow modification to only the uppermost layer of the polymer, to a depth of several nanometres, without affecting properties in bulk. Surface chemical composition and physical properties, such as wettability, roughness and morphology, which affect the release mechanisms of the drug, can be substantially altered by various approaches to treatment, including introducing different functional groups, crosslinking polymer chains via activated species of inert gas and plasma deposition of coatings. ${ }^{[12-16]}$

Hagiwara et al. demonstrated significant reduction in the burst effect and release rate of a drug from ethylene-vinyl acetate copolymer. ${ }^{[8]}$ Their process introduced a crosslinking layer into the polymer surface by applying several activated species of inert gas. Despite substantial increase in surface wettability, the crosslinking network functioned as an effective barrier for restricting drug diffusion. On the contrary, conducting plasma treatment of poly(lactic-co-glycolic acid) (PLGA) films with the inert gas of argon in combination with oxygen induced incorporation of hydrophilic carbonyl groups, rather than instigating polymer backbone crosslinking, thereby accelerating the release rate of the drug. ${ }^{[17]}$

In fact, several studies have attempted to achieve a desirable release rate by depositing a thin coating that acts as rate-limiting barrier for the drug. ${ }^{[18]}$ Most such works detail application of radio-frequency induction plasma deposition of a thin layer of $n$-butyl 
methacrylate on various materials, an action which eliminates the unwanted burst effect and fine-tunes release kinetics according to the thickness of the layer. ${ }^{[9,19,20]}$ Moreover, a fluorinated layer formed by atmospheric pressure glow plasma was examined, although any potential application is limited by the environmental impact of the precursors utilized. ${ }^{[21]}$ However, there remains a significant lack of information on setting the desirable release kinetics of a drug from biodegradable materials by plasma treatment, despite contemporary widespread use in control release devices. Research should also take into account alteration in hydrolytic degradability that often accompanies plasma treatment, which can crucially affect the mechanisms of drug release as well as their acceptability in medical application. ${ }^{[22]}$

The research presented herein focuses on modifying the release profile and eliminating the undesirable burst release of the model drug Temozolomide (TMZ) from two forms of biodegradable polyester by plasma treatment. The polyesters in question were either based on polylactic acid (PLA) or its copolymer - polyester urethane (PEU), with polyethylene glycol linked via urethane bonds. According to the works referenced above, both materials are considered promising biomaterials possessing characteristics for controlled release. ${ }^{[2,23]}$

Two plasma treatment techniques were applied in order to modify the surfaces of the materials. The aim was to achieve extreme diversity in wettability status, which is presumed to be a key factor in controlling the release rate of the drug. ${ }^{[24]}$ A diffuse coplanar surface barrier discharge (DCSBD) system - with air as the gaseous medium - 
was applied to hydrophilize the samples. While capacitively coupled radio-frequency

(CCRF) discharge plasma - in an argon atmosphere with hexamethyldisiloxane

(HMDSO) - as a precursor was employed to create the hydrophobic surface coating layer

Surface properties related to such plasma modification were studied via water contact angle measurements, nanoindentation and X-ray photoelectron spectroscopy (XPS). The effect of plasma treatment on the hydrolytic degradation of the materials was investigated by chromatographic techniques, whereas the release kinetics of the model drug TMZ were analysed by spectroscopic methods.

\section{MATERIALS AND METHODS}

\subsection{Materials}

L-lactic acid (LA), 80\% water solution and PEG $\left(\mathrm{M}_{\mathrm{w}}=380-420 \mathrm{~g} \cdot \mathrm{mol}^{-1}\right)$ were purchased from Merck, Hohensbrunn, Germany. Tin(II) 2-ethylhexanoate ( $\left.\operatorname{Sn}(\mathrm{Oct})_{2}\right)$, 95\%; 1,6hexamethylene diisocyanate (HMDI, in liquid state), 98\%; dimethyl sulphoxide; and the precursor Hexamethyldisiloxane (HMDSO), 98.5\%, were sourced from Sigma-Aldrich, Steinheim, Germany. The solvents, comprising acetone, methanol and ethanol (all analytical-grade), were obtained from IPL Petr Lukes, Uhersky Brod, Czechia.

The drug used for the control release test was the anti-cancer agent temozolomide (TMZ), $>98 \%$, supplied by Sigma-Aldrich.

\subsubsection{Preparation of Polylactic Acid (PLA)}


PLA was synthesized through direct melt polycondensation of lactic acid. Initially, $50 \mathrm{~g}$ of $80 \%$ D,L-lactic acid (optical purity 99.9\%, Penta) was placed into a two-neck flask equipped with a condenser. The contents were stirred and heated for $4 \mathrm{~h}$ at $160^{\circ} \mathrm{C}$ under reduced pressure at $20 \mathrm{kPa}$. After $4 \mathrm{~h}, 0.5 \%(\mathrm{w} / \mathrm{w})$ of the catalyst, tin(II) octoate, was added, after which the pressure was reduced to $0.1 \mathrm{kPa}$ and the reaction left to continue for a further $24 \mathrm{~h}$. Finally, the product was cooled, dissolved in acetone, precipitated from water/methanol solution (1:1), filtered, washed several times with distilled water and ethanol, and then dried in a vacuum oven at $55^{\circ} \mathrm{C}$ and $15 \mathrm{kPa}$ for $48 \mathrm{~h}$.

\subsubsection{Preparation of Polyester Urethane (PEU)}

Firstly, poly(lactic acid)-poly(ethylene oxide) (PLA-PEG) prepolymer was synthesized as follows. $100 \mathrm{ml}$ of L-LA was added into a $250 \mathrm{ml}$, two-neck distillation flask equipped with a Teflon stirrer. The flask was then connected to a condenser and placed in an oil bath. Initially, dehydration of the L-LA solution at $160^{\circ} \mathrm{C}$ took place, under a reduced pressure of $20 \mathrm{kPa}$ for $4 \mathrm{~h}$. Then $0.5 \mathrm{wt} . \% \mathrm{Sn}(\mathrm{Oct})_{2}$ and $7.5 \mathrm{wt} . \% \mathrm{PEG}$ were added, and the reaction continued for $6 \mathrm{~h}$ at $10 \mathrm{kPa}$. Afterwards, the pressure was reduced to $3 \mathrm{kPa}$ for another $10 \mathrm{~h}$. The resultant hot melt was poured out onto aluminium foil and cooled.

Subsequently, in order to prepare the final product, $30 \mathrm{~g}$ of the PLA-PEG that had been created was placed into a $250 \mathrm{ml}$, two-neck flask equipped with a mechanical stirrer. The material was slowly heated to the predetermined temperature of $160^{\circ} \mathrm{C}$, under an $\mathrm{N}_{2}$ atmosphere. Once the mixture had completely melted, 1,6-hexamethylene diisocyanate (HMDI) was added at an amount equivalent to the ratio of 2.3 for NCO 
(related to $\mathrm{NCO}$ groups from the $\mathrm{HMDI}$ ) to $\mathrm{OH}$ (related to $\mathrm{OH}$ groups from the PEG), and the reaction continued for 30min. The quantities of chain-linkers were calculated and expressed as a ratio of $\mathrm{NCO}$ (from the diisocyanates) to $\mathrm{OH}$ (from the PEG groups).

Immediately after adding the chain-linker, the polymer melt became visibly viscous. The resultant product was cooled, dissolved in acetone, precipitated into a water/methanol mixture (1:1), then filtered and dried in a vacuum at $30^{\circ} \mathrm{C}$ for $24 \mathrm{~h}$.

\subsection{Methods}

\subsubsection{Preparation of the Polymeric Thin Layer}

The PLA and PEU materials were dissolved in DMSO at the concentration of $0.7 \mathrm{mg} \cdot \mathrm{ml}^{-1}$ and $0.4 \mathrm{mg} \cdot \mathrm{ml}^{-1}$, respectively, after which $2.5 \% \mathrm{w} / \mathrm{w}$ TMZ related to the weight of the given polymer was added. $60 \mu \mathrm{l}$ of the solution was then deposited on a glass sheet $(2.5 \times$ $2.5 \mathrm{~cm}$ ) and spread by a blade to create a thin layer. Finally, the samples were dried in a vacuum oven at $20^{\circ} \mathrm{C}$ under the pressure of $1 \mathrm{kPA}$ to evaporate the DMSO. The thickness of the resulting thin layers was determined by ellipsometry, and discovered to be $40.5 \mu \mathrm{m}$ and $26.2 \mu \mathrm{m}$ for PLA and PEU, respectively.

\subsection{Plasma Treatment}

\section{Hydrophilization}

As previously mentioned, plasma hydrophilization of the surface was carried out by utilizing the diffuse coplanar surface barrier discharge (DCSBD) system, with air as the gaseous medium, at atmospheric pressure and room temperature. The polymeric thin layer on the glass substrate was fixed to the sample holder at the distance of $0.1 \mathrm{~mm}$ from 
a series of parallel metallic electrodes, which had been set inside ceramic dielectric material placed in a glass chamber. Samples were treated for an appropriate duration at the plasma power of $300 \mathrm{~W} .^{[25]}$

\section{Hydrophobization}

The act of hydrophobizing the surface of samples was performed by capacitively coupled radio-frequency $(\mathrm{CCRF})$ plasma, operated at a reduced pressure of $80 \mathrm{~Pa}$. The system consisted of two circular brass electrodes, $240 \mathrm{~mm}$ in diameter, placed in a symmetrical arrangement, $10 \mathrm{~mm}$ apart, between which the CCRF plasma was formed. The CCRF plasma reactor was set to a voltage of $2 \mathrm{kV}$, while frequency equalled $13.56 \mathrm{MHz}$, current intensity was $0.6 \mathrm{~mA}$, and the maximum power of the CCRF plasma source stood at 600 W. The HMDSO was bubbled by argon at a flow rate of $10 \mathrm{ml} / \mathrm{min}$. (Messer-Griessheim, 5.0), and introduced into the plasma reactor.

\subsection{Characterization}

\subsubsection{Water Contact Angle and Surface Energy}

Contact angles for the untreated and plasma-treated thin layers were gauged by static contact angle measurement (on Kruss G1 apparatus). Surface energy $\left(\gamma_{\mathrm{s}}\right)$, dispersive $\left(\gamma_{\mathrm{s}}{ }^{\mathrm{d}}\right)$ and polar $\left(\gamma_{s}^{\mathrm{p}}\right)$ components were calculated by the Owens-Wendt method, using deionized water/diiodomethane (purity 99\%, Sigma) contact angles. The volume of the droplet was $3 \mu \mathrm{l}$ for both liquids. Contact angles were expressed as the averages of 5 measurements from different sites on the thin layer, taking into consideration standard 
deviation. Measurements were performed immediately after plasma treatment, and after having been left for 7 days in a desiccator at $5^{\circ} \mathrm{C}$.

\subsubsection{X-Ray Photoelectron Spectroscopy (XPS)}

XPS signals were recorded on a Thermo Scientific K-Alpha XPS system (Thermo Fisher Scientific, UK), equipped with a micro-focused, monochromatic Al K $\alpha$ X-ray source (1486.6 eV). An X-ray beam of size $400 \mu \mathrm{m}$ was used at $6 \mathrm{~mA} \times 12 \mathrm{kV}$. The spectra were acquired in the constant analyser energy mode, with pass energy set to $200 \mathrm{eV}$ for the survey. Narrow regions were collected using the snapshot acquisition mode ( $150 \mathrm{eV}$ pass energy), enabling rapid collection of data ( $5 \mathrm{~s}$ per region). Charge compensation was achieved via the flood gun of the system, which provided low energy electrons $(\sim 0 \mathrm{eV})$ and low energy argon ions (20 eV) from a single source. Thermo Scientific Avantage software, version 5.952 (Thermo Fisher Scientific), was applied for digital acquisition and data processing. Spectral calibration was determined by the automated calibration routine and internal $\mathrm{Au}, \mathrm{Ag}$ and $\mathrm{Cu}$ standards supplied with the K-Alpha system.

Surface compositions (in atomic per cent) were determined by considering the integrated peak areas of the detected atoms and the respective sensitivity factors. The fractional concentration of a particular element $A$ was computed using:

$$
\% A=\frac{I_{A} / s_{A}}{\sum I_{n} / s_{n}} \times 100 \%
$$

where $I_{n}$ and $s_{n}$ are the integrated peak areas and Scofield sensitivity factors corrected for analyser transmission, respectively. 


\subsubsection{Surface Morphology}

The topographic properties of the samples were analysed on a Triboindenter device (TI750: Hysitron, Minneapolis, USA). This tool is able to scan the surface of the material, resulting in surface topography images. The piezo scanner of the Triboindenter has the capacity to scan $70 \mu \mathrm{m} \times 70 \mu \mathrm{m}$, or less, of a square area by using a Berkovich diamond indenter with a tip radius of $150 \mathrm{~nm}$. Tip induced wear patterns were observed as a function of the scanning frequency (almost $0-3 \mathrm{~Hz}$ ) and normal load (almost $0-8$ $\mu \mathrm{N})$. The scanning speed of the tip depends on the frequency and sean size. A square 30 $\mu \mathrm{m} \times 30 \mu \mathrm{m}$ area of the surface was scanned at the contact load of $2 \mu \mathrm{N}$. For the scan size $30 \mu \mathrm{m} \times 30 \mu \mathrm{m}$, the velocity of the tip equalled $10 \mu \mathrm{m} / \mathrm{sec}$ at the scanning frequency of $0.17 \mathrm{~Hz}$.

\subsubsection{Abiotic Hydrolysis}

The extent and rate of material hydrolysis was determined at $37^{\circ} \mathrm{C}$ for 4 weeks. Each sample on the glass substrate was placed in a weighing bottle equipped with a groundglass lid, to which $10 \mathrm{ml}$ of PBS (pH 7.4) was added. At appropriate intervals, $10 \mathrm{ml}$ aliquots of the medium were taken and analysed for dissolved organic carbon (on a TOCL Analyser, Shimadzu). The samples were replaced with fresh buffer solution. The percentage of carbon in the material required for calculating hydrolysis was determined by elemental analysis on a Flash EA 1112 series analyser by Thermo Electron Corp., in the configuration CHNS/O. 
The experiment was carried out in three replications for each sample. In parallel, the materials were also analysed by gel permeation chromatography (GPC) for molecular weight.

The evolution of weight average molecular weight $\left(M_{w}\right)$ during abiotic hydrolysis was modelled using a first-order kinetic equation adopted from a reference ${ }^{[26]}$, which describes the random scission mechanism for hydrolysis. The analytical solution of the model is given by Equation 2:

$M_{w, t}=M_{w, 0} \cdot e^{-u t}$

where $M_{w, t}$ and $M_{w, 0}\left(\mathrm{~g} \cdot \mathrm{mol}^{-1}\right)$ represent final and initial weight average $M_{w}$ at time $t$ and $t=0$, respectively; the parameter $u\left(\right.$ day $\left.^{-1}\right)$ is the rate constant for abiotic hydrolysis.

\subsubsection{Gel Permeation Chromatography}

The weight average molecular weight $\left(M_{w}\right)$ and molecular weight distribution of samples and changes to the same during degradation tests were analysed by gel permeation chromatography (GPC) on an HT-GPC 220 system (Agilent), equipped with a dual detection system ("RI" refractive index and "VIS" viscosity detectors). Samples were dissolved in THF ( 2 mg.ml-1) overnight. Separation and detection took place on a series of mixed columns $(1 \times B, 1 \times D, 1 x E)(300 \times 7.8 \mathrm{~mm}$, Polymer Laboratories $)$. Analyses were carried out at $40^{\circ} \mathrm{C}$ in THF, with a flow rate of $1.0 \mathrm{ml} \cdot \mathrm{min}-1$ and loading volume of $100 \mu \mathrm{l}$. The GPC system was calibrated with narrow polystyrene standards ranging from 580 to $3000000 \mathrm{~g} \cdot \mathrm{mol}-1$ (Polymer Laboratories Ltd., UK). The molecular weight averages $\left(M_{w}, M_{n}\right)$ and molecular-weight dispersity $\left(\mathrm{MWD}=M_{w} / M_{n}\right)$ were calculated 
with the aid of a polystyrene standard "universal" calibration curve. Values of intrinsic viscosity $\eta$ were obtained directly from the viscosity detector. All data processing was carried out within Cirrus software.

\subsubsection{Release Tests}

The treated plasma and untreated plasma samples on the glass substrate were immersed into $5 \mathrm{ml}$ of phosphate buffer saline (PBS, $7.4 \mathrm{pH}$ ) and incubated at $37^{\circ} \mathrm{C}$. All experiments were carried out in triplicates. The entire volume was removed at predetermined intervals, the used PBS was replaced with $5 \mathrm{ml}$ of fresh PBS, and then filtration took place through a $0.22 \mu \mathrm{m}$ syringe PTFE filter for subsequent analysis. The concentration of the TMZ released was determined on a UV-VIS (Cary 300 UV-Vis, Agilent) spectrophotometer at 325 and $263 \mathrm{~nm}$. The amount of TMZ released (TR) was calculated by the following Equation 3:

$T M Z \%=\frac{T_{t}}{T_{0}} \times 100$

The data obtained from the TMZ release experiments were analysed by applying the standard semi-empirical exponential equation, the purpose being to describe and assess the influence of plasma treatment on release kinetics:

$\frac{T_{t}}{T_{\infty}}=K t^{n}+C$

where $T_{t}$ is the amount of TMZ released at time $t$, and $T_{\infty}$ is the total amount of agent in the polymer layer. Parameter $n$ is a diffusional exponent describing the mechanism of release pertaining to the geometry of the system. For the polymer film, $n$ actually ceased at 0.5 , thereby indicating diffusion-controlled drug release; $n$ equal to 1.0 corresponds to 
degradation (swelling) release mechanisms, and values for $n$ between 0.5 and 1.0

comprise both phenomena in the release mechanism (anomalous transport). The kinetic constant $K$ relates to the release rate of the drug in the initial phase, and parameter $C$ gives information on the occurrence and intensity of the burst phenomena. ${ }^{[27]}$

\section{RESULTS}

\subsection{Effect of Plasma Treatment on Wettability and Surface Energy}

The PLA surfaces prior to and after plasma treatment at various times were examined by taking contact angle and surface energy measurement. The contact angle for deionized water $\left(\theta_{W}\right)$ was measured twice: immediately after plasma exposition had occurred, and following 7 days of storing the specimen in silica-gel at $5^{\circ} \mathrm{C}$, the latter containing a desiccator. All surface free energies $\left(\gamma_{\mathrm{s}}\right.$ and its components - the dispersive and polar part $\left.\left(\gamma_{\mathrm{s}}^{\mathrm{d}}, \gamma_{\mathrm{s}}^{\mathrm{p}}\right)\right)$ were deduced from the contact angles for water and diiodomethane using the Owens-Wendt method. On the basis of the results obtained, determination was made of the optimum duration of plasma treatment for maximum hydrophilization and hydrophobization, which was subsequently applied throughout the study. The untreated surfaces of PLA and PEU samples showed similar values for water contact angles $\left(75^{\circ}\right.$ and $78^{\circ}$ ). The $\theta_{W}$ of PLA was in general agreement with the chemical structure of the tested samples, as well as with previously published data. ${ }^{[28]}$ Interestingly, the PEU material exhibited a significantly higher $\theta_{W}$ than recorded in a previous study, ${ }^{[22]}$ probably reflecting the longer time available for crystallization and reorientation of the polar group from the surface into the bulk during preparation of the thin layers. 


\subsubsection{Hydrophilization}

The materials were hydrophilized by DCSBD plasma in an air atmosphere with an exposure time that gradually increased from $2 \mathrm{~s}$ to $20 \mathrm{~s}$ in order to achieve maximum hydrophilization. Figure 1 presents the resultant values for the contact angles of deionized water $\left(\theta_{W}\right)$. A strong decline in $\theta_{W}$ was detected even following $2 \mathrm{~s}$ of plasma treatment for both materials, as a consequence of introducing polar groups (containing oxygen) into the polymer surfaces. In the case of PLA, longer treatment times brought about a slight decrease in $\theta_{W}$, dropping to a minimum of $42^{\circ}$ at 10 s. The subsequent rise in $\theta_{W}$ at $20 \mathrm{~s}$ might be induced by the crosslinking of polymer chains, itself caused by function groups formed deeper in the material. ${ }^{[29]}$ PEU displayed a more pronounced hydrophilic tendency, with $\theta_{W}$ equalling about $37^{\circ}$ throughout the period of the plasma treatment applied, probably due to easier incorporation of the polar units into the surface than seen in PLA. A significantly better hydrophilization effect was achieved for PLA in comparison with a previous study, where commercial PLA was exposed to the same plasma conditions. ${ }^{[30]}$

The rise in surface free energy $\left(\gamma_{s}\right)$ was mainly due to its polar component $\left(\gamma_{\mathrm{s}}^{\mathrm{p}}\right)$, which increased several times, while the dispersive component $\left(\gamma_{\mathrm{s}}^{\mathrm{d}}\right)$ slightly decreased after treatment (Figure 2). This implied the formation of groups containing polar carboxyl on the surface of materials. ${ }^{[31]}$ As expected, $\theta_{W}$ measurements for materials after 7 days of ageing revealed a certain recovery in hydrophobicity. The data for $\gamma_{s}$ both showed that $\gamma_{s}{ }^{d}$ returned approximately to its original value and a slight decrease in $\gamma_{\mathrm{s}}^{\mathrm{p}}$ occurred. These findings may have been induced by the polar groups created on surface, the latter 
undergoing reorientation into the bulk of the material so as to minimize interfacial energy in a non-polar environment, as in agreement with previous studies. ${ }^{[32,33]}$ Nevertheless, hydrophilicity still remained considerably higher than in the untreated materials, the best wettability appearing after approximately $10 \mathrm{~s}$ of plasma treatment for both materials.

\subsubsection{Hydrophobization}

Hydrophobization of the material was carried out with CCRF plasma in an argon atmosphere, with HMDSO as the monomer employed for coating the surface. Exposure time was gradually increased in duration from 2 to $10 \mathrm{~min}$. to achieve maximum hydrophobization. Figure 3 depicts the contact angles for water $\left(\theta_{W}\right)$ on the surface treated with HMDSO plasma over time. A significant increase in $\theta_{W}$, signifying successful deposition of the hydrophobic siloxane layer, was evident even after $1 \mathrm{~min}$. of treatment for both materials. Afterwards, the $\theta_{W}$ of PLA tended to rise gradually over time, reaching a maximum of WCA $117^{\circ}$ at 10 min. of HMDSO plasma deposition. In the case of PEU, water repellence further substantially improved after $10 \mathrm{~s}$ of plasma treatment, followed by a slight increase to a maximum $\theta_{W}$ of about $120^{\circ}$ after $20 \mathrm{~s}$. The resulting WCA of the siloxane-based coating was in accordance with the given chemical structure and previously published data. ${ }^{[34]}$

The siloxane coatings decrease the $\gamma_{\mathrm{s}}$ of the polymer surfaces due to decrease in the $\gamma_{\mathrm{s}}^{\mathrm{p}}$ and $\gamma_{\mathrm{s}}{ }^{\mathrm{d}}$ components of the surface energy (Figure 4). In both materials $\gamma_{\mathrm{s}}{ }^{\mathrm{p}}$ almost completely disappeared completely after 5 min. of plasma treatment, probably as a consequence of a well distributed formation of siloxane units on the surface. With such 
low surface energy, the dispersive component accounts for any electronic interaction, e.g. weak Wan der Waals plays a more substantial role than polar interactions. Repeating the $\theta_{W}$ measurement after 7 days showed certain ageing effects in both materials. While the $\theta_{W}$ of samples exposed to plasma for up to 3 min. tended towards a slight decrease in hydrophobicity, it was intensified at longer durations of plasma treatment. Rise in hydrophobicity upon ageing of a plasma-polymerized HMDSO layer has been observed previously, ${ }^{[35,36]}$ explained as mainly due to reorientation of the polar groups into the bulk and migrations of low-molecular-weight fractions to the surface. The optimum time for maximum hydrophobization of both materials alongside a minimal duration of plasma treatment was observed to be 5 minutes, and this time was applied for the material over further experiments.

\subsection{Surface Analysis}

Both materials were analysed by XPS prior to plasma treatment and after either $5 \mathrm{~s}$ of hydrophilization or 5 min. of hydrophobization, the reason being to evaluate chemical changes in the elemental composition of the surface. The acquired survey spectra and narrow regions of $\mathrm{C} 1 \mathrm{~s}, \mathrm{O} 1 \mathrm{~s}$ and $\mathrm{Si} 2 \mathrm{p}$ spectra for both materials are given in Figures 5 and 6. The corresponding atomic compositions of the surfaces are summarized in Table 1. The survey spectra for the untreated material indicated the presence of carbon $(\mathrm{C} 1 \mathrm{~s}$ peak at $\sim 285 \mathrm{eV}$ ) and oxygen $(\mathrm{O} 1 \mathrm{~s}$ at $\sim 533 \mathrm{eV})$, as well as nitrogen (N1s peak at $\sim 400 \mathrm{eV}$ ) in the case of PEU, the composition of which was in accordance with a previous investigation. ${ }^{[25]}$ The presence detected of a certain amount of silicon (Si) arose through contamination of the materials during preparation. The C1s spectra also underwent 
deconvolution into three functional components: $\mathrm{C}-\mathrm{C}, \mathrm{C}-\mathrm{O}$ and $\mathrm{O}-\mathrm{C}=\mathrm{O}$, at approximately $285 \mathrm{eV}, 287 \mathrm{eV}$ and $289 \mathrm{eV}$, respectively (Table 1). As expected, both plasmahydrophilized samples exhibited more enriched $\mathrm{C}-\mathrm{O}$ and $\mathrm{O}-\mathrm{C}=\mathrm{O}$ groups, whereas the amount of $\mathrm{C}-\mathrm{C}$ was reduced. Concurrently, the atomic composition of $\mathrm{O}$ increased at the expense of $\mathrm{C}$, which decreased. Hence this confirmed the introduction of a new hydrophilic carbonyl group on the surface, caused by DCSBD plasma in the atmosphere of air. Moreover, nitrogen was detected on the surface of the PLA as a consequence of plasma treatment in the atmosphere of air. ${ }^{[25]}$ The decline in Si contamination might also indicate the surface etching effect exerted by plasma treatment.

A different situation arose in the case of the plasma-hydrophobized samples. In both materials XPS analysis indicated a high content of silicon, i.e. constituent elements of the HMDSO monomer, and a higher atomic composition of oxygen, as well as a lower content of carbon than the untreated samples (Table 1). Such modification is also reflected in the curve form of the C1s spectra, which showed a dramatic decline in the content of the groups $\mathrm{C}-\mathrm{O}$ and $\mathrm{O}-\mathrm{C}=\mathrm{O}$ and an increased $\mathrm{C}-\mathrm{C}$ bond of up to more than $80 \%$ after HMDSO plasma deposition. The success of the hydrophobization process was evidenced by a significant decrease in hydrophilic carbonyl groups. It was possible to estimate the chemical composition of the deposited layer from the spectra for individual elements (Figure 6). The plasma deposition of HMDSO was characterized by the formation of $(\mathrm{CH}-)_{3} \mathrm{Si}(-\mathrm{O})_{1}$ groups with binding energy at $101.5 \mathrm{eV}$ on the surface of the polymer. ${ }^{[37]}$ The peak at approximately $100.6 \mathrm{eV}$ characterized the silicon atom pertaining to siloxane moieties directly attached to the carbon atom (Si-C). ${ }^{[38]}$ Indeed, it is 
known that the presence of oxygen in the plasma process results in deposition of newly formed silicon-oxygen moieties on the surface. Evidence that oxygen was bound to the silicon transpired through the shift in the centroid of the Si2p peak, i.e. $(\mathrm{CH}-)_{2} \mathrm{Si}(-\mathrm{O})_{2}$ to $102.1 \mathrm{eV},(\mathrm{CH}-)_{1} \mathrm{Si}(-\mathrm{O})_{3}$ to $102.8 \mathrm{eV}$ and $\mathrm{Si}(\mathrm{O})_{4}$ to $103.4 \mathrm{eV} \cdot{ }^{[37]}$ The position of the $\mathrm{Si} 2 \mathrm{p}$ peak for both materials (Figure 6C) implied that there was rapid formation of siliconoxygen moieties, as deposited on the polymer surface during plasma treatment. The fact that there was a great number of oxygen atoms bound to the silicon atom was also assumed from the heightened atomic composition of the oxygen (Table 1). This finding was more pronounced for hydrophobized PEU due to the shift in the Si2p peak to higher binding energy values and the heightened atomic composition of oxygen in comparison with hydrophobized PLA.

\subsection{Surface Morphology}

Figure 7 shows topography scans for both materials preceding and following plasma treatment after 7 days of storage. Prior to treatment, the surface of the PLA seemed relatively smooth, while the surface of PEU was rougher with evident protrusions. Significant differences in surface morphology were found in the PEU after hydrophilization. Any large protrusions that had been discerned on the untreated sample were broken up, and morphology tended towards greater roughness with a high proportion of smaller protrusions; these came about through the etching effect of energetic ion bombardment and surface oxidation by the reactive species present in the plasma. The etching effect of plasma seemed to be insignificant in the case of PLA, although this could have been caused by relaxation of surface morphology during the 
period of storage. In both cases, such a strong plasma effect could lead to destruction of the drug near to the surface. Hydrophobization brought about changes in morphology and increased the roughness of both samples, in comparison with the untreated materials that is, thereby indicating non-homogenous deposition of silicon-based moieties. In fact, the varying degree of thickness in the layer on the surface of the polymer could ultimately lead to anomalous release kinetics for the given drug.

\subsection{Hydrolysis of the Polymeric Thin Layers}

The sensitivity of materials to abiotic hydrolysis is considered a key factor for application in medical bioresorbable systems. In order to investigate the effect of plasma on the degradability of the materials, a hydrolysis experiment was set up in phosphate-buffered saline (PBS) at $37^{\circ} \mathrm{C}$. The mechanism of hydrolysis and its kinetics were studied at molecular level by GPC techniques. Afterwards, analysis was made of the accumulation of dissolved organic carbon products from such hydrolysis, so as to determine the loss in polymer mass.

\subsubsection{Changes in Molecular-Weight Distribution}

Figure 8 ( $\mathrm{A}$ and $\mathrm{B}$ ) displays the evolution of molecular weight over the first 28 days of abiotic hydrolysis. The data obtained were evaluated by applying the Equation 4 for firstorder kinetics, describing the random scission of ester bonds typical for low-molecularweight polyesters. The parameters of the Equation, along with the correlation coefficient $\mathrm{R}$, are listed in Table 2. The coefficients of determination $\left(R^{2}\right)$ over 0.94 for the all samples indicate the adequacy of the model. 
Slight diminishment in weight average molecular weight $\left(M_{w}\right)$ was detected in both materials after plasma hydrophilization, unlike in the untreated samples, as a consequence of reaction between the polymer radicals formed by plasma with the atmospheric oxygen. In contrast, plasma hydrophobization led to a rise in $M_{w}$, probably due to recombination of plasma-induced polymer radicals in the argon atmosphere. ${ }^{[39]}$

The drop in $M_{w}$ induced by hydrolysis over 28 days was more pronounced for PEU, which concurs with previous studies, thereby suggesting the simpler hydrolysis of PEU in comparison with PLA. ${ }^{[22]}$ Compared to the untreated materials, the rate of chain scission expressed by the hydrolysis constant $u$ was shown to be slightly accelerated in both hydrophilized materials, while it was significantly decelerated (by almost twofold) for hydrophobized PLA (Table 2). Both such effects are attributable to the different wettability levels of the samples after plasma treatment had occurred, whereby control is facilitated for the rate of diffusion of water into the polymer matrix, this being indispensable to activating hydrolytic degradation.

Both materials possessed narrow, unimodal and relatively symmetrical molecular-weight distribution (MWD), the polydispersity (PDI) indexes standing at around 1.6 and 1.4 for PEU and PLA, respectively (Figure 9). Following plasma hydrophobization, MWD broadened out to show PDIs of approximately 2.0 and 2.3 for PLA and PEU, respectively. The decrease in $M_{w}$ was accompanied by only moderate narrowing in MWD for all the PLA samples. Meanwhile, the PEU samples demonstrated rapid changes in 
MWD, characterized by an overall shift in distribution towards lesser $M_{w}$ values, and gradual diminishment in peak was observed. Substances with $M_{w}$ values of several hundred, hence likely to just exceed the water solubility limit for the fragment of the oligomers pertaining to the polymers, were released into the water, thus accelerating disintegration of the polymer matrix.

\subsubsection{Release of Water Soluble Hydrolysis Products}

Measurements for accumulation of dissolved organic carbon, as a result of hydrolysis of the materials, are in accordance with previous findings. Due to the polymers possessing characteristics of low molecular weight, the onset of hydrolysis was discernible from commencement of the experiment (Figure 10). After four weeks, the more easily hydrolysed PEU exceeded a level of $40 \%$, whereas PLA merely exhibited hydrolysis of about $15 \%$. The more intensive hydrolysis of both hydrophilized samples (PLA and PEU) corresponded with the faster shift in $M_{w}$ towards lower values and the formation of detectable water-soluble fragments. The slightly higher values for hydrolysis in the hydrophobized samples at the outset of the process might be attributable to release of a low-molecular-weight fragment formed during plasma treatment and/or the presence of the siloxane-based coating.

The conclusion is that the plasma treatments investigated do not hinder both materials from acceptability in applications requiring hydrolytic degradability.

\subsection{Temozolomide Release Kinetics}


The cumulative release of temozolomide (TMZ) from the thin layers of untreated and plasma-treated PLA and PEU are plotted in Figures 11 and 12, respectively. The experimental data as at the first 24 hours was analysed by applying the common semiempirical exponential equation to describe and assess initial rate and burst release (Figure 11 and 12, inner graphs). Table 3 lists the kinetics parameters and coefficient of determination obtained via Equation 4, along with values for correlation of determination $\left(\mathrm{R}^{2}\right)$. If the values for $\mathrm{R}$ are high, then a good fit is indicated for the exponential equations to the TMZ release profiles gained for all the samples.

As can be seen, the release of TMZ from both untreated materials was characterized by a non-linear biphasic profile, where initial rapid release within several hours was followed by a considerably slower phase over a few days. A steeper release profile was observed for PEU, characterized by a time corresponding to $50 \%$ of agent release $\left(t_{50}\right)$ at approximately 6.4 hours, in comparison with PLA exhibiting $t_{50}$ at over 19 hours. The release exponent was calculated as equal to 0.462 and 0.433 for PLA and PEU, respectively; these were close to 0.5 , indicating that TMZ release in the first phase was likely to have been controlled by diffusion in both materials. The moderate, initial burst release was characterized by a relatively high parameter - $C$ equalled $9.0 \%$ and $6.3 \%$, thereby indicating the amount of TMZ release over the first 0.5 hours, as well as by the high rate constants $(K)$ of $10.5 \mathrm{~h}^{-1}$ and $19.6 \mathrm{~h}^{-1}$ for PLA and PEU, respectively. The faster release rate from PEU might be attributed to lesser thickness and easier disintegration of the material, as demonstrated in the results from hydrolysis. 
Compared to pristine PLA, the release kinetics for TMZ from plasma-hydrophilized PLA were noticeably modified. The release curve in the initial phase was seen to be more linear, and achieved an almost desirable zero-order release profile, which was characterized by a nearly constant rate of drug release over the first 100 hours, when more than $70 \%$ of the drug was released. Advantageously, the release of $50 \%$ of TMZ $\left(t_{50}\right)$ was also prolonged to almost 62 hours. The calculated diffusion exponent of $n=$ 0.812 suggested that the release mechanism was altered from being clearly associated with diffusion to that of anomalous control, which comprises, besides diffusion, participation by degradation of the materials. ${ }^{[27]}$ Plasma treatment brought about a further positive effect in terms of reducing the undesirable burst-effect phenomena, characterized by significantly lower parameters - $C=1.41 \%$ and initial release rate $K=1.41 \mathrm{~h}^{-1}$, in comparison with the original material.

Due to the greater wettability of the PLA surface, one would have expected a more rapid release rate for the drug. However, the hypothesis is that a certain level of crosslinking, deeper in structure, created a barrier for drug penetration, ${ }^{[40,8]}$ in addition to which the high-energy plasma destruction of the drug near the surface might have suppressed the burst effect and the rate of drug release. In contrast, plasma hydrophilization of PEU did not substantially alter the release kinetics for TMZ, unlike the untreated sample, and still adhered to the biphasic non-linear profile.

In relation to plasma hydrophobization, deposition of siloxane on the polymeric surface instigated significant inhibition of the initial burst release of TMZ in both materials, also 
suppressing a diminishing release rate for the drug (Figures 11 and 12). In particular, a completely different release profile was demonstrated in the PLA-treated film. In the first phase, a release of about $10 \%$ of TMZ was detected within almost 50 hours. Afterwards, in the second phase, the release rate accelerated over the following 120 hours, during which $70 \%$ of the loaded TMZ was released. The remnant of the drug was released over the final 120 hours, exhibiting a diminishing rate of release. Analysis of the release curve in the initial phase revealed that the process was still governed by diffusion $(n=0.487)$. Nevertheless, due to the silicone barrier created on the surface, the burst effect was reduced to almost zero $(0.04 \%)$. Furthermore, compared to untreated PLA, the rate of release over the initial 24 hours slowed down several times, as characterized by $K=1.41$ $\mathrm{h}^{-1}$. The duration necessary to release $50 \%$ of the TMZ $\left(t_{50}\right)$ extended to approximately 90 hours, which was almost five times longer than for untreated PLA. The contour of the release curve suggested that the hydrophobic coating - acting as a rate-limiting barrier in the initial phase - might gradually disintegrate, thereby permitting rapid release in the second phase.

In the case of the PEU-hydrophobized sample, the reduction in the release rate was not as dramatic as for PLA, although there was still significant slowdown of the burst effect in comparison with untreated PEU. Results from analysis of the initial phase of release showed that the burst constant decreased by more than 10 times $(\mathrm{C}=0.53 \%)$, and the release rate by approximately two-fold $\left(K=9.54 \mathrm{~h}^{-1}\right)$. As a consequence, the time for $50 \%$ drug release $\left(t_{50}\right)$ was also prolonged by more than 25 hours. The biphasic release profile comprised two main phases: i. initial faster release controlled by diffusion 
$(n=0.499)$, when about $25 \%$ of TMZ was released within 8 hours; ii. subsequent slower release characterized by more desirable zero-order release kinetics. During this stationary phase, almost $50 \%$ of the TMZ was released at an almost constant rate over the following 40 hours. Afterwards, the remainder of the TMZ was released at an ever slower rate.

Eliminating the initial burst release in various polymer systems via a diffusional barrier deposited by plasma has been previously demonstrated in the literature. ${ }^{[9,10,20 \text { and 21] }}$ Moreover, the majority of such studies have shown reduction in initial and long-term release rates, as a result of the tightly bound layer. Contrarily, in the systems presented herein, gradual deterioration of the outer coating enabled acceleration of drug release, which in the second phase approximately adhered to the rate demonstrated by the untreated material. A temporary layer such as this could prove advantageous in applications for release requiring postponed onset of the drug.

\section{CONCLUSION}

The study herein demonstrated the effect exhibited on the release kinetics of the drug temozolomide (TMZ) by plasma hydrophilization and hydrophobization of thin, biodegradable, low-molecular-weight polyester films - polylactic acid (PLA) and polyester urethane (PEU). A DCSBD system, with air as the gaseous medium, was applied to hydrophilize the surface of the materials, while CCRF discharge plasma in an argon atmosphere with hexamethyldisiloxane (HMDSO) was used to coat the surface with a hydrophobic siloxane-based layer. The hydrophilization technique, which significantly increased the wettability of the polymer surface through incorporating 
hydrophilic carbonyl groups, was shown to be an effective tool for modifying the release kinetics of TMZ from PLA, in contrast with the untreated material. Positive aspects comprised reduction in the undesirable burst effect and slowdown in the release rate of the drug; these were likely to result from destruction of the drug near the surface and the crosslinking of polymer chains deeper in the structure. Moreover, the modified release kinetics achieved a desirable, almost zero-order release profile. In the case of PEU, the effect of modification on release kinetics was negligible. Carrying out plasma hydrophobization of both polymer surfaces, which gave rise to a strong effect of water repellence through deposition of silicon-based moieties, led to significant inhibition of both the initial burst release and the diminishing release rate of TMZ. In the case of PLA, gradual deterioration of the layer that had been created permitted acceleration of drug release, which approximately adhered to the release rate for untreated material in the later phase. The hydrolytic degradability of the materials was slightly enhanced after hydrophilization and, vice versa, reduced after hydrophobization; this was especially true for PLA as a consequence of its wettability properties having been modified. The conclusion is that, by utilizing the plasma technique described herein, a particular release profile could be tuned to suit the desired administration of the given drug without dramatic change occurring in hydrolytic degradability, which would otherwise limit any medical application.

\section{ACKNOWLEDGEMENTS}

This work was financially supported by the Czech Science Foundation (Grant No. 1508287Y), the Ministry of Agriculture of the Czech Republic (Grant No. QJ1310254) and 
the Ministry of Education, Youth and Sports of the Czech Republic (GrantsNo. LO1504 and CZ.1.05/2.1.00/19.0409). The work was also supported by the Ministry of Education, Science, Research and Sports of the Slovak Republic and the Slovak Academy of Sciences, as part of the "VEGA" project (ref. 02/0199/14) and by the Slovak Research and Development Agency under contract No. APVV-14-0518

\section{REFERENCES}

[1] Zanini, S., Grimoldi, E. and Riccardi, C. Mater. Chem. Phys. 138, 850 (2013).

[2] Pavelkova, A., Kucharczyk, P., Stloukal, P., Koutny, M. Polym. Adv. Technol. $25,595(2014)$

[3] Zhao, X., Hu, Ch., Pan, G. and Cui, W. Part. Part. Syst. Charact. 32, 529 (2015).

[4] Birajdar, M. S., and Lee, J. Chem. Eng. J. 288, 1 (2016).

[5] Huang, X. and Brazel, Ch. S. J. Controlled Release 73, 121 (2001).

[6] Woo, B. H., Kostanski, J. W., Gebrekidan, S., Dani, B. A., Thanoo, B. C. and DeLuca, $\quad$ P. P. J. Control Release 75, 307 (2001).

[7] Berkland, C., King, M., Cox, A., Kim, K. K. and Pack D. W. J. Control Release 82, 137 (2002).

[8] Hagiwara, K., Hasebe, T. and Hotta A. Surf. Coat. Technol. 15, 318 (2013).

[9] Kwok, C. S., Horbett, T. A. and Ratner, B. D. J. Control Release 62, 301-311 (1999).

[10] Yoshida, S., Hagiwara, K., Hasebe, T. and Hotta, A. Surf. Coat. Technol. 233, 99 (2013). 
[11] Kuzuya, M., Sasai, Y., Yamauchi, Y. and Kondo, S. J. Photopolym. Sci. Technol. 21, 785 (2008).

[12] Mozetič, M., Primc, G., Vesel, A., Zaplotnik, R., Modic, M., Junkar, I., Recek, N., Klanjšek Gunde, M., Guhy, L., Sunkara, M. K., Assensio, M. C., Milošević, S., Lehocky, M., Sedlarik, V., Gorjanc, M., Kutasi, K. and Stana-Kleinschek, K. Plasma Sources Sci. Technol. 24, 1 (2015).

[13] Mozetič, M., Ostrikov, K., Ruzic, D. N., Curreli, D., Cvelbar, U., Vesel, A., Primc, G., Leisch, M., Jousten, K., Malyshev, O. B., Hendricks, J. H., Kövér, L., Tagliaferro, A., Conde, O., Silvestre, A. J., Giapintzakis, J., Buljan, M., Radić, N., Dražić, G., Bernstorff, S., Biederman, H., Kylián, O., Hanuš, J., Miloševič, S., Galtayries, A., Dietrich, P., Unger, W., Lehocky, M., Sedlarik, V., Stana-Kleinschek, K., Drmota-Petrič, A., Pireaux, J. J., Rogers, J. W. and Anderle, M. J. Phys. D: Appl. Phys. 47, (2014).

[14] Vrlinic, T., Debarnot, D., Legeay, G., Coudreuse, A., El Moualij, B., Zorzi, W., Perret-Liaudet, A., Quadrio, I., Mozetic, M. and Poncin-Epaillard, F. Macromol. Biosci. $12,830(2012)$.

[15] Doliška, A., Vesel, A., Kolar, M., Stana-Kleinschek, K., Mozetič. M., Surf. Interface Anal. 44, 56 (2012).

[16] Asadinezhad, A., Lehocký, M., Sáha, P., Mozetič, M. Materials, 5, 2937 (2012).

[17] Mogal, V. T., Yin, Ch. S., O’Rorke, R., Boujday, S., Méthivier, Ch., Venkatraman, S. S. and Steele, T. W. J. ACS Appl. Mater. Interfaces 6, 5749 (2014).

[18] Zanini, S., Grimoldi, E. and Riccardi, C. Mater. Chem. and Phys. 138, 850 (2013) 
[19] Hendricks, S. K., Kwok, C., Shen, M., Horbett, T. A., Ratner, B. D. and Bryers, J. D. J. Biomed. Mater. Res., Part A 50, 160 (2000).

[20] Yuan, Y., Liu, Ch., Zhang, Y., Yin, M. and Shi, Ch. Surf. Coat. Technol. 201, 6861 (2007).

[21] Tanaka, K., Kogoma, M. and Ogawa, Y. Thin Solid Films 506-507, 159 (2006)

[22] Kucharczyk, P., Pavelková, A., Stloukal, P. and Sedlarík, V. Polym. Degrad. Stab. 129, 222 (2016).

[23] Kucharczyk, P., Hnatkova, E., Dvorak, Z. and Sedlarik, V., Polym. Degrad. Stab. 98, 150 (2013).

[24] Koennings, S., Berié, A., Tessmar, J., Blunk, T. and Goepferich, A. J. Controlled Release 119, 173 (2007).

[25] Asadinezhad, A., Novák, I., Lehocký, M., Sedlařík, V., Vesel, A., Junkar, I., Sáha, P. and Chodák, I. Colloids Surf., B 77, 246 (2010).

[26] Vieira, A. C., Vieira, J. C., Ferra, J. M., Magalhães, F. D., Guedes, R. M. and Marques, A. T. J. Mech. Behav. Biomed. 4, 451 (2011)

[27] Siepmann, J. and Peppas, N.A. Adv. Drug Delivery Rev. 64, 163 (2012)

[28] Paragkumar N, T., Dellacherie, E. and Six., J.-L Appl. Surf. Sci. 253, 2758 (2006)

[29] Hergelová, B., Zahoranová, A., Kováčik, D. and Černák, M. WDS'13 Proceedings of Contributed Papers, Part III, Prague 2013.

[30] Hergelová, B., Zahoranová, A., Kováčik, D., Stupavská, M. and Černák, M. Open Chem.13, 564 (2015). 
[31] Leroux, F., Campagne, Ch., Perwuelz, A. and Gengembre, L. Surf. Coat. Technol. 203, 3178 (2009).

[32] Morent, R., De Geyter, N., Leys, C., Gengembre, L. and Payen, E. Surf. Coat. Technol. 201, 7847 (2007)

[33] Kim, K. S., Ryu, Ch. M., Park, Ch. S., Sur, G. S. and Park, Ch. E. Polymer 44, $6287(2003)$

[34] Ziari, Z., Nouicer, I., Sahli, S., Rebiai, S., Bellel, A., Segui, Y. and Raynaud., P. Vacuum 93, $31(2013)$

[35] Trinh, Q. H., Lee, S. B. and Mok, Y. S. AIChE J. 60, 829 (2014)

[36] Bónová, L., Zahoranová, A., Kováčik, D. and Černák, M. Chem. Pap. 106, 1431 (2012)

[37] Alexander, M.R., Short, R.D., Jones, F.R., Michaeli, W. and Blomfield, C.J. Appl. Surf. Sci. 137, 179 (1999)

[38] Gengenbach, T. R. and Griesser, H. J. Polymer 40, 5079 (1999)

[39] Desmet, T., Morent, R., Geyter, N. D., Schacht, Ch. L. E. and Dubruel, P. Biomacromolecules 10, 2351 (2009)

[40] Morent, R., De Geyter, N., Trentesaux, M., Gengembre, L., Dubruel, P., Leys, C. and Payen, E. Plasma Chem. and Plasma Process, 30, 525 (2010) 
Table 1. Surface elemental compositions of polylactic acid (PLA) and polyester urethane (PEU) prior to and following plasma treatment; via XPS analysis (mean \pm standard deviation).

\begin{tabular}{|c|c|c|c|c|c|c|c|c|}
\hline Sample & $\mathrm{O} 1 \mathrm{~s}$ & $\mathrm{C} 1 \mathrm{~s}$ & Si2p & N1s & S2s & $\begin{array}{l}\mathrm{C} 1 \mathrm{~s} \\
\mathrm{C}-\mathrm{C}\end{array}$ & $\begin{array}{l}\mathrm{C} 1 \mathrm{~s} \\
\mathrm{C}-\mathrm{O}\end{array}$ & $\begin{array}{l}\mathrm{C} 1 \mathrm{~s} \\
\mathrm{OC}=\mathrm{O}\end{array}$ \\
\hline PLA untreated & $\begin{array}{l}34.1 \\
( \pm 0.2)\end{array}$ & $\begin{array}{l}60.5 \\
( \pm 0.5)\end{array}$ & $\begin{array}{l}5.4 \\
( \pm 0.7)\end{array}$ & & & $\begin{array}{l}46.5 \\
( \pm 1.2)\end{array}$ & $\begin{array}{l}26.2 \\
( \pm 0.7)\end{array}$ & $\begin{array}{l}27.3 \\
( \pm 0.5)\end{array}$ \\
\hline $\begin{array}{l}\text { PLA } \\
\text { hydrophilized }\end{array}$ & $\begin{array}{l}39.5 \\
( \pm 0.1)\end{array}$ & $\begin{array}{l}53.50 \\
( \pm 0.8)\end{array}$ & $\begin{array}{l}1.3 \\
( \pm 0.0)\end{array}$ & $\begin{array}{l}3.2 \\
( \pm 0.3)\end{array}$ & $\begin{array}{l}2.7 \\
( \pm 0.3)\end{array}$ & $\begin{array}{l}40.3 \\
( \pm 1.9)\end{array}$ & $\begin{array}{l}29.4 \\
( \pm 0.5)\end{array}$ & $\begin{array}{l}30.3 \\
( \pm 1.6)\end{array}$ \\
\hline $\begin{array}{l}\text { PLA } \\
\text { hydrophobized }\end{array}$ & $\begin{array}{l}47.5 \\
( \pm 0.4)\end{array}$ & $\begin{array}{l}24.4 \\
( \pm 1.1)\end{array}$ & $\begin{array}{l}24.5 \\
( \pm 0.6)\end{array}$ & $\begin{array}{l}1.9 \\
( \pm 0.6)\end{array}$ & $( \pm 0.5)$ & $\begin{array}{l}87.3 \\
( \pm 1.4)\end{array}$ & $\begin{array}{l}10.1 \\
( \pm 1.4)\end{array}$ & $\begin{array}{l}2.5 \\
( \pm 0.9)\end{array}$ \\
\hline PEU untreated & $\begin{array}{l}30.2 \\
( \pm 0.4)\end{array}$ & $\begin{array}{l}62.8 \\
( \pm 0.2)\end{array}$ & $( \pm 0.4)$ & $\begin{array}{l}1.6 \\
( \pm 0.2)\end{array}$ & & $\begin{array}{l}51.8 \\
( \pm 1.2)\end{array}$ & $\begin{array}{l}26.7 \\
( \pm 0.7)\end{array}$ & $\begin{array}{l}21.5 \\
( \pm 0.5)\end{array}$ \\
\hline $\begin{array}{l}\text { PEU } \\
\text { hydrophilized }\end{array}$ & $\begin{array}{l}34.9 \\
( \pm 0.1)\end{array}$ & & 3.8 & $\begin{array}{l}2.4 \\
( \pm 0.3)\end{array}$ & $\begin{array}{l}0.5 \\
( \pm 0.0)\end{array}$ & $\begin{array}{l}41.1 \\
( \pm 0.2)\end{array}$ & $\begin{array}{l}31.4 \\
( \pm 0.1)\end{array}$ & $\begin{array}{l}27.5 \\
( \pm 0.1)\end{array}$ \\
\hline $\begin{array}{l}\text { PEU } \\
\text { hydrophobized }\end{array}$ & $\begin{array}{l}58.7 \\
( \pm 0.9)\end{array}$ & $\begin{array}{l}11.9 \\
( \pm 0.5)\end{array}$ & $\begin{array}{l}28.5 \\
( \pm 0.8)\end{array}$ & $\begin{array}{l}0.5 \\
( \pm 0.0)\end{array}$ & $\begin{array}{l}0.6 \\
( \pm 0.1)\end{array}$ & $\begin{array}{l}82.5 \\
( \pm 1.1)\end{array}$ & $\begin{array}{l}13.3 \\
( \pm 0.5)\end{array}$ & $\begin{array}{l}4.2 \\
( \pm 0.8)\end{array}$ \\
\hline
\end{tabular}


Table 2. Parameters for the model of first order kinetics and coefficients of determination $\left(R^{2}\right)$ for random scission of the polylactic acid (PLA) and polyester urethane (PEU) nanocomposites.

\begin{tabular}{|l|l|l|l|}
\hline Sample & $M_{w_{-} 0^{\mathrm{a}}}\left(\mathrm{g} \cdot \mathrm{mol}^{-1}\right)$ & $u^{\mathrm{b}}\left(\mathrm{day}^{-1}\right)$ & $\mathrm{R}^{2}$ \\
\hline PLA - untreated & 10670 & 0.0182 & 0.9734 \\
\hline PLA - hydrophilized & 9480 & 0.0198 & 0.9840 \\
\hline PLA - & 11330 & 0.0096 & 0.9500 \\
hydrophobized & & & 0.9729 \\
\hline PEU - untreated & 12570 & 0.0498 & 0.9931 \\
\hline PEU - hydrophilized & 12380 & 0.0595 & 0.9426 \\
\hline PEU - & 13851 & 0.0510 & \\
\hline hydrophobized & & & \\
\hline
\end{tabular}

${ }^{a}$ Initial weight average $M_{w}$ at time $t=0 ;{ }^{b}$ rate constant of abiotic hydrolysis. 
Table 3. Parameters for fitting the model equation to the TMZ Release Data.

\begin{tabular}{|l|l|l|l|l|}
\hline Sample & \multicolumn{1}{|l|}{$\mathrm{K}^{-\mathrm{h}^{-}}$} & $\mathrm{n}^{\mathrm{b}}$ & $\mathrm{C}(\%)^{\mathrm{c}}$ & $\mathrm{R}^{\mathrm{d}}$ \\
\hline PLA - untreated & 10.49 & 0.462 & 9.00 & 0.997 \\
\hline PLA - & 1.71 & 0.812 & 1.41 & 0.999 \\
\hline hydrophilized & & & & \\
\hline PLA - & 1.41 & 0.487 & 0.04 & 0.994 \\
\hline PEU - untreated & 19.62 & 0.433 & 6.13 & 0.980 \\
\hline PEU - & 15.10 & 0.496 & 6.95 & 0.978 \\
\hline hydrophilized & & & & \\
\hline PEU - \\
hydrophobized
\end{tabular}

${ }^{a}$ Release constant; ${ }^{b}$ diff usional exponent; ${ }^{c}$ initial burst constant; ${ }^{c}$ diff usional exponent; ${ }^{\mathrm{d}}$ correlation coefficient; ${ }^{\mathrm{e}}$ time corresponding to $50 \%$ of agent release. 
Figure 1. Water contact angles for polylactic acid (PLA) (A) and polyester urethane (PEU) (B) for different durations of plasma treatment, measured immediately after treatment (0 days) and after 1 week (7 days).
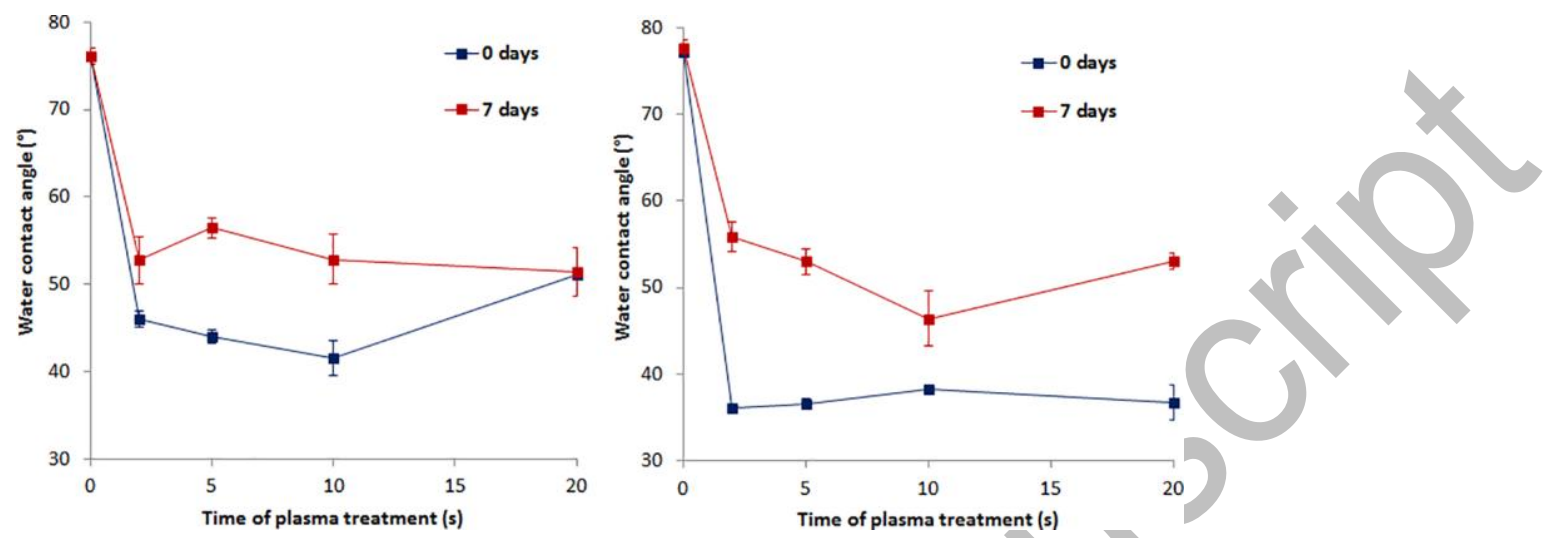
Figure 2. Surface energy of polylactic acid (PLA) (A) and polyester urethane (PEU) (B) for different durations of plasma treatment, measured immediately after treatment $(0$ days) and after 1 week (7 days).
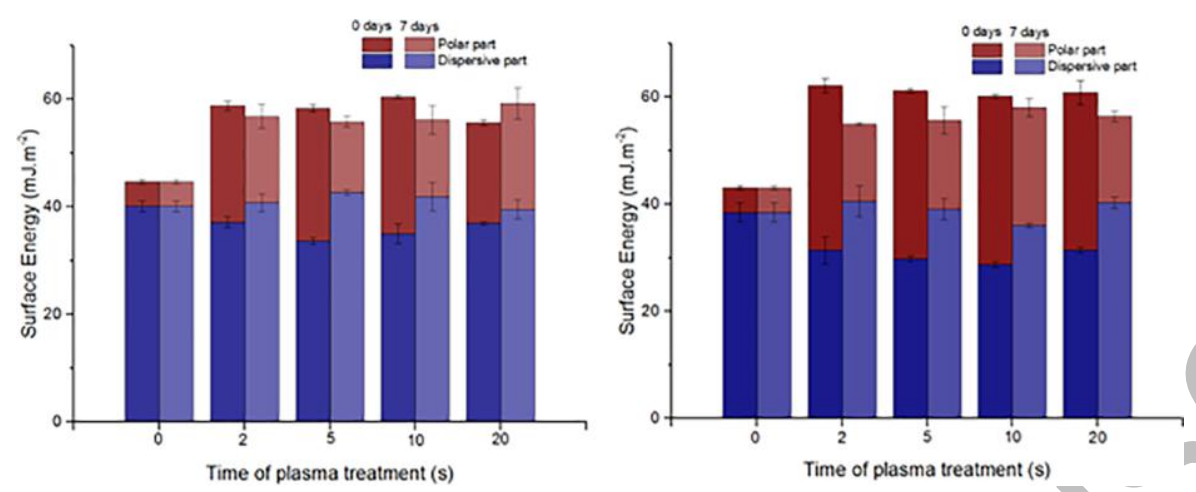
Figure 3. Water contact angles for polylactic acid (PLA) (A) and polyester urethane (PEU) (B) for different durations of plasma treatment, measured immediately after treatment ( 0 days) and after 7 days.
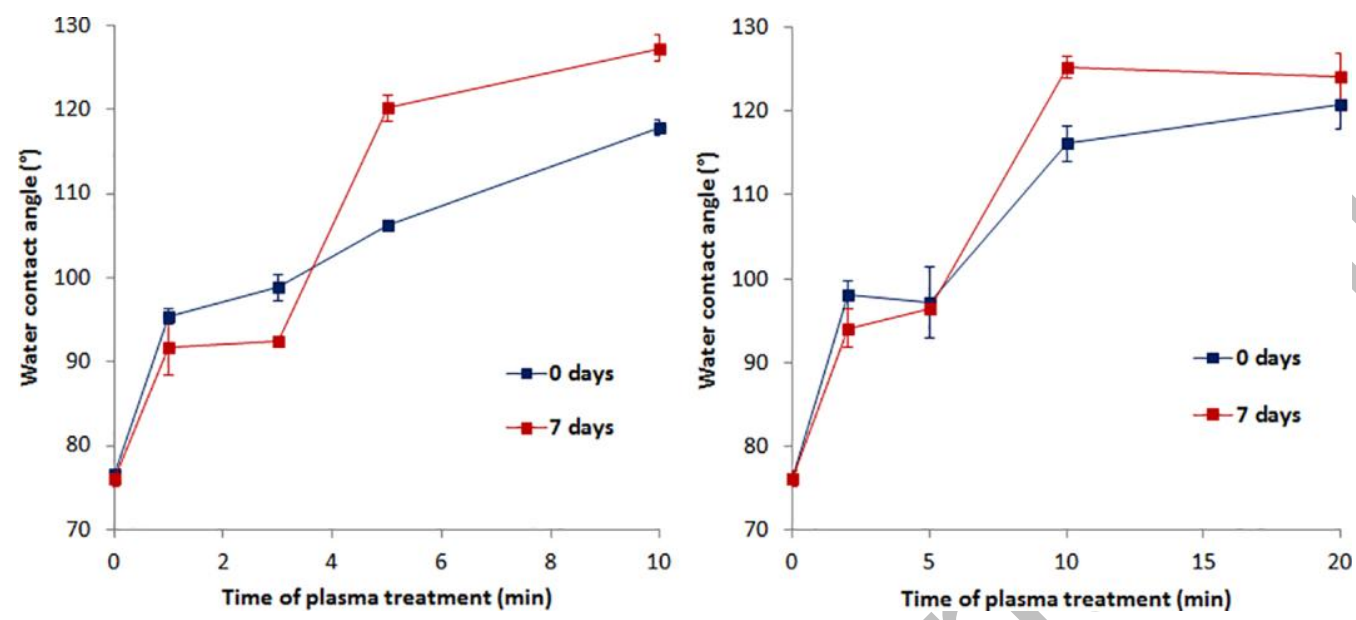
Figure 4. Surface energy of polylactic acid (PLA) (A) and polyester urethane (PEU) (B) for different durations of plasma treatment, measured immediately after treatment $(0$ days) and after 7 days.
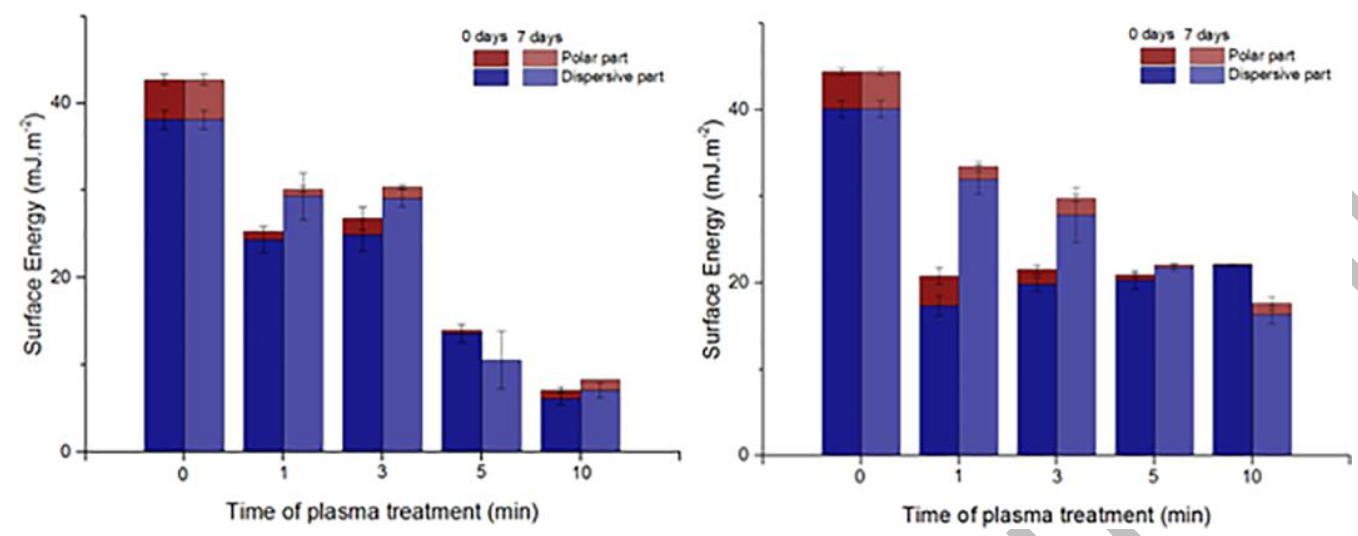
Figure 5. XPS survey-scan spectra for polylactic acid (PLA) (A) and polyester urethane (PEU) (B) prior to and following plasma treatment.
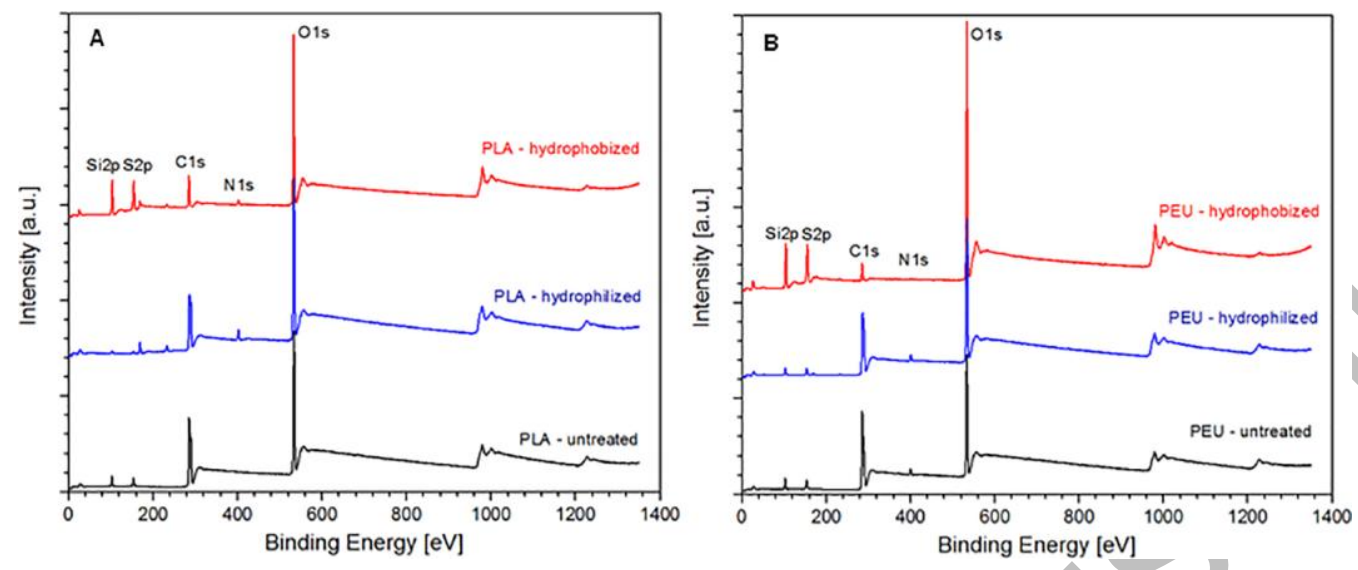
Figure 6. C 1s (A), O 1s(B) and Si 2p (C) spectra for polylactic acid (PLA) and polyester urethane (PEU) prior to plasma treatment and following plasma treatment.
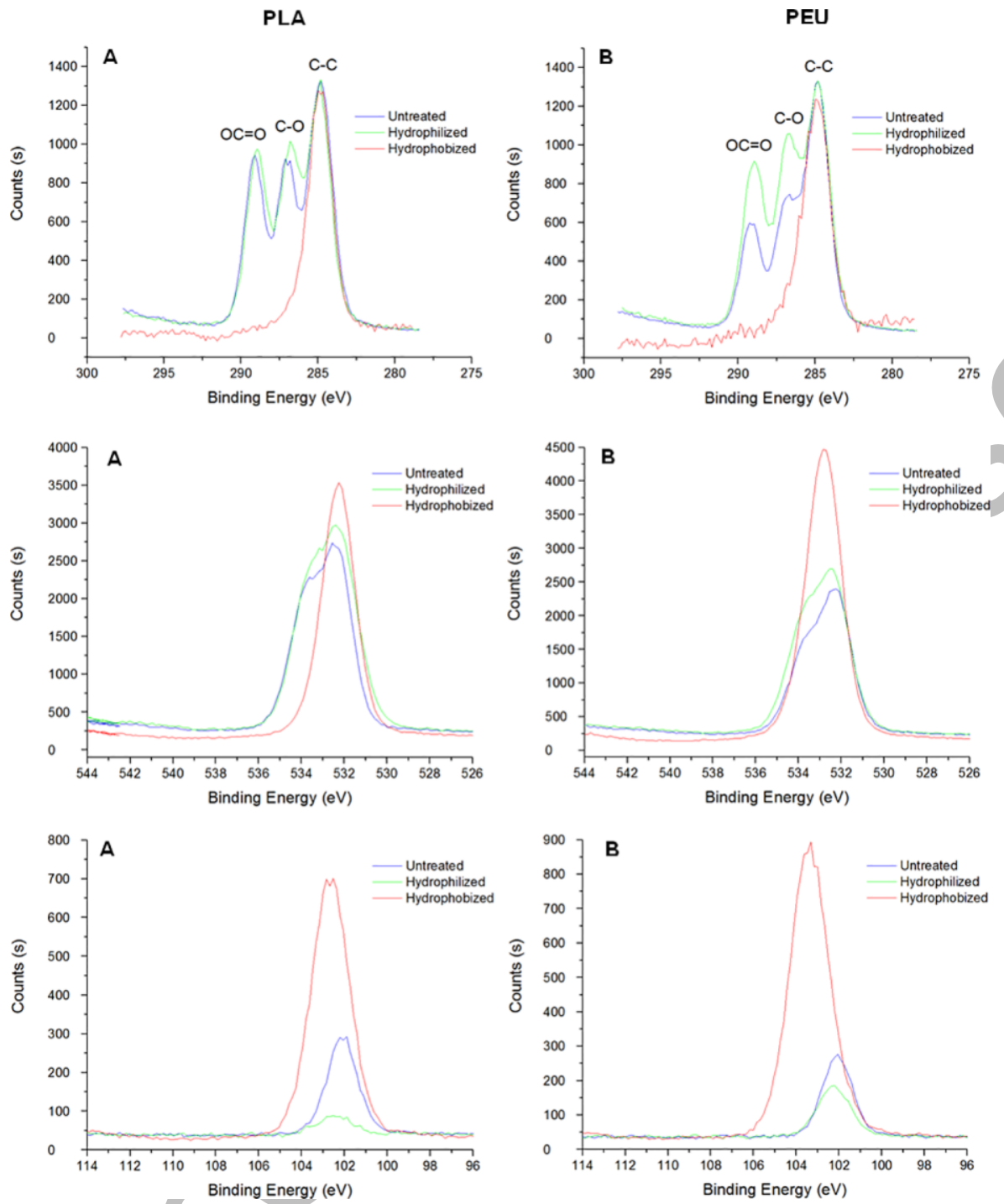
Figure 7. Nano-indented 3D topography images for thin layers of untreated (A) plasma, and plasma-hydrophilized (B) and plasma-hydrophobized (C) polylactic acid (PLA) and polyester urethane (PEU).
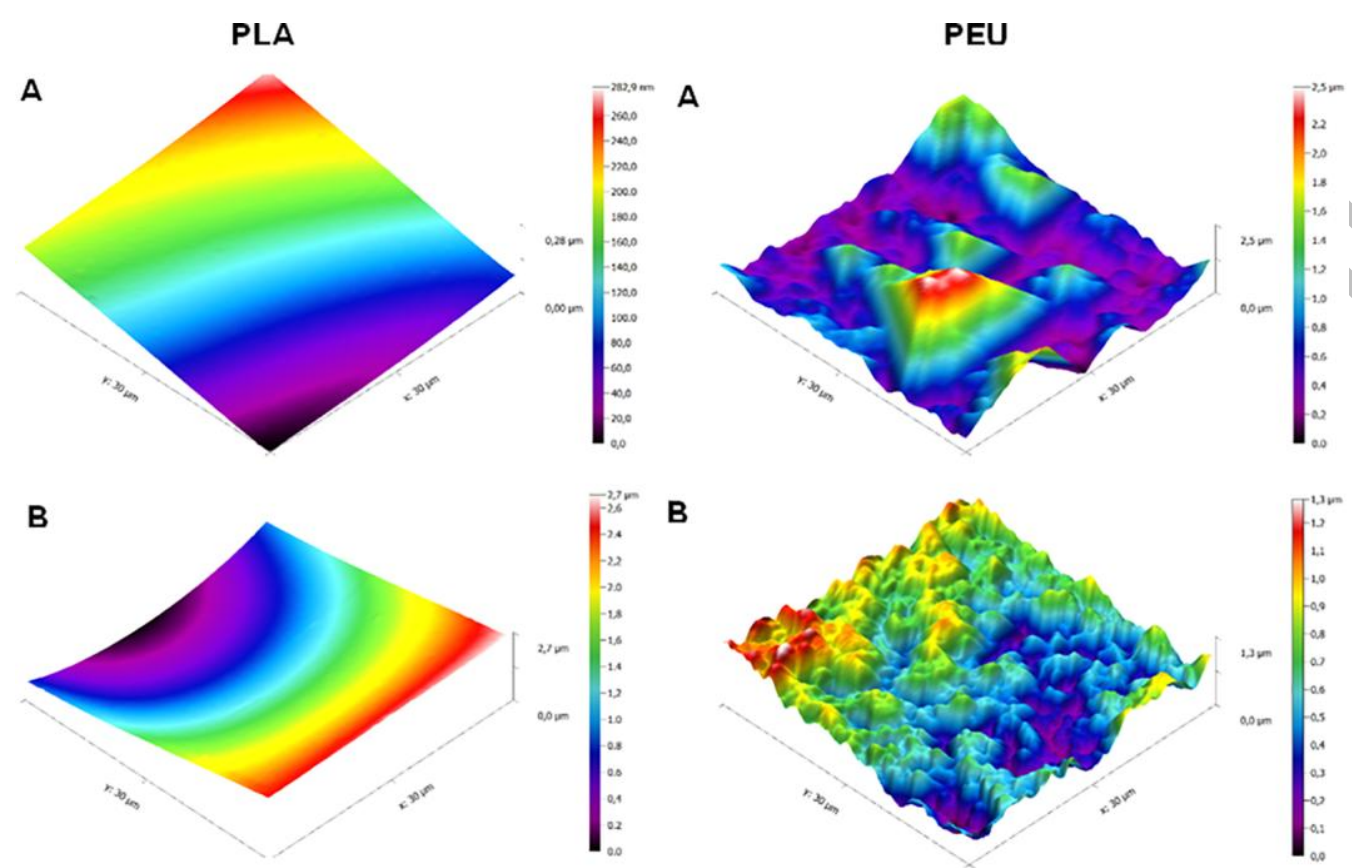

B
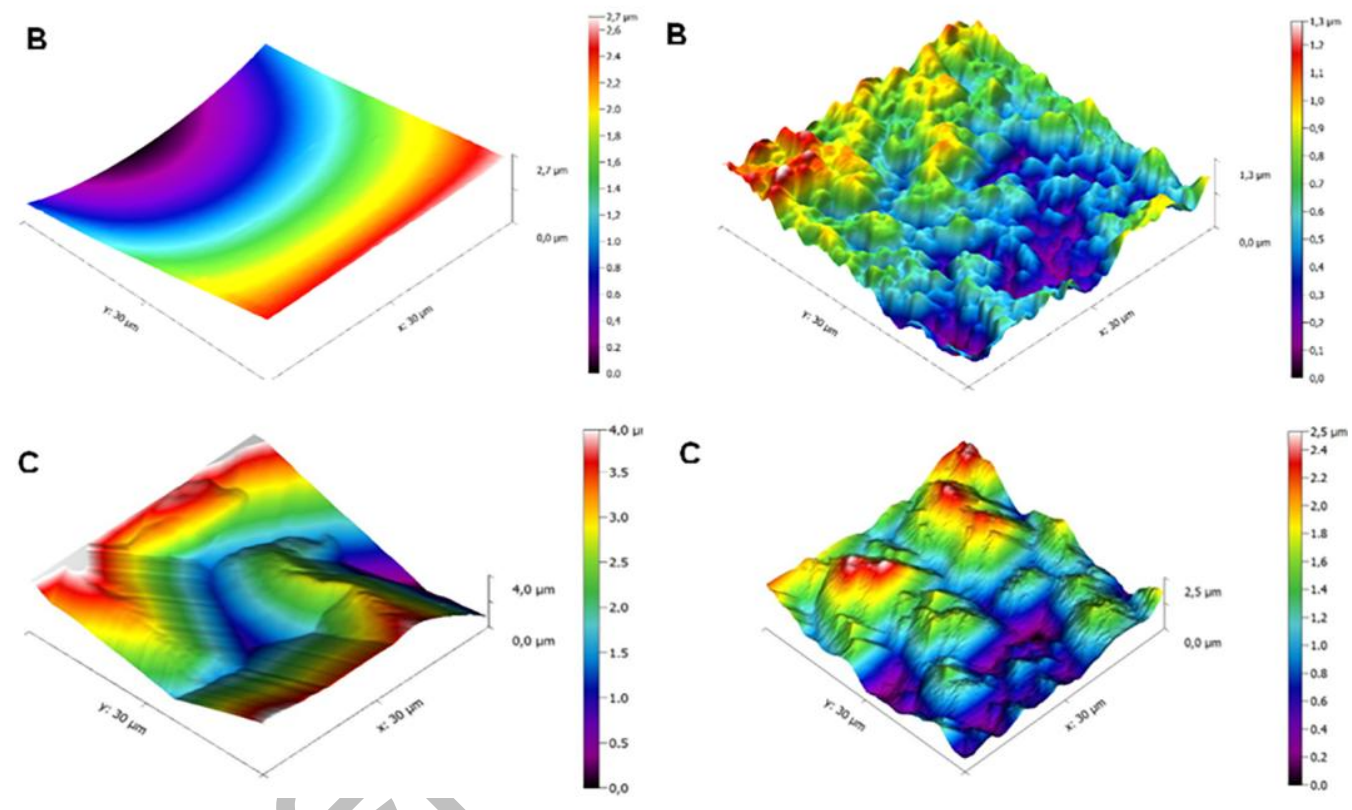

C

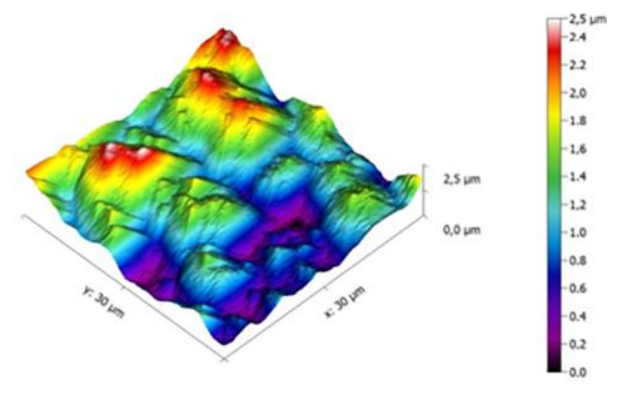


Figure 8. Molecular-weight evolution of thin layers of untreated and plasma-treated polylactic acid (PLA) (A) and polyester urethane (PEU) (B) in PBS buffer at $\mathrm{pH}=7.4$. Experimental data (squares) are fitted with the model (lines) according to Equation 4.
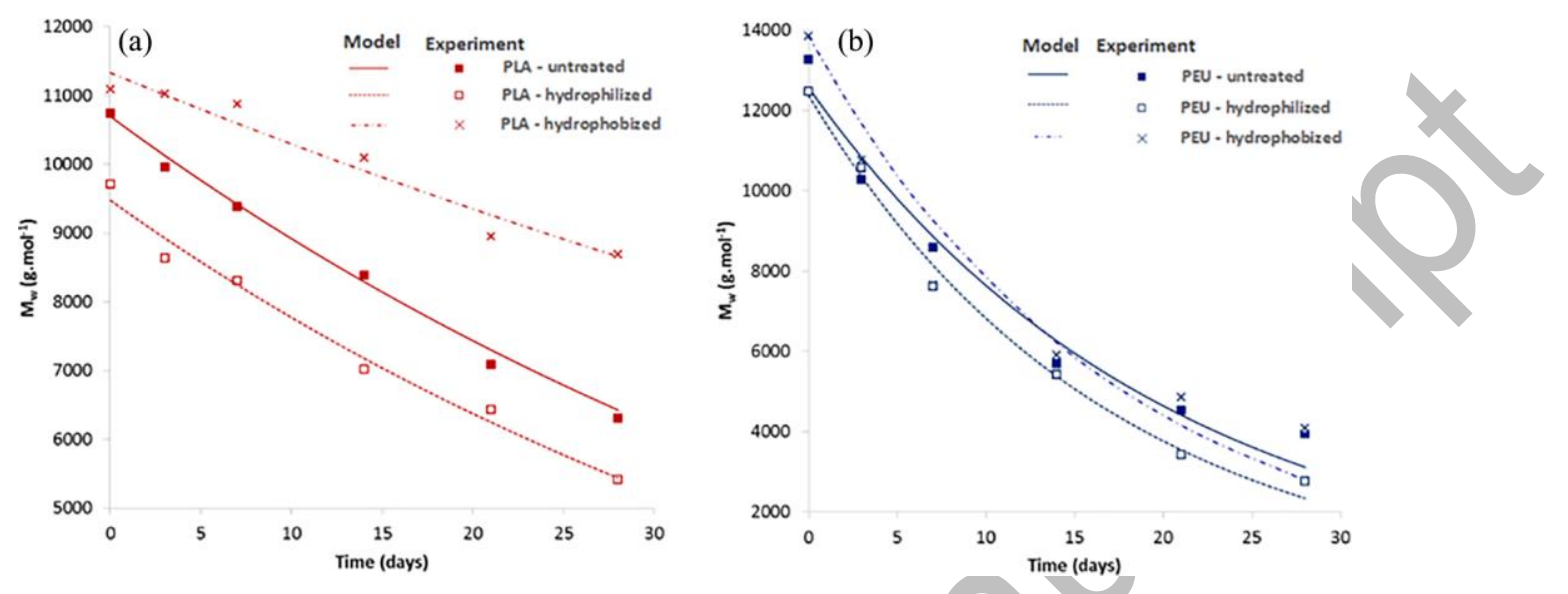
Figure 9. Evolution of molecular-weight distribution of polylactic acid (PLA) and polyester urethane (PEU) prior to plasma treatment (A), plasma hydrophilization (B) and plasma hydrophobization (C) during abiotic hydrolysis.
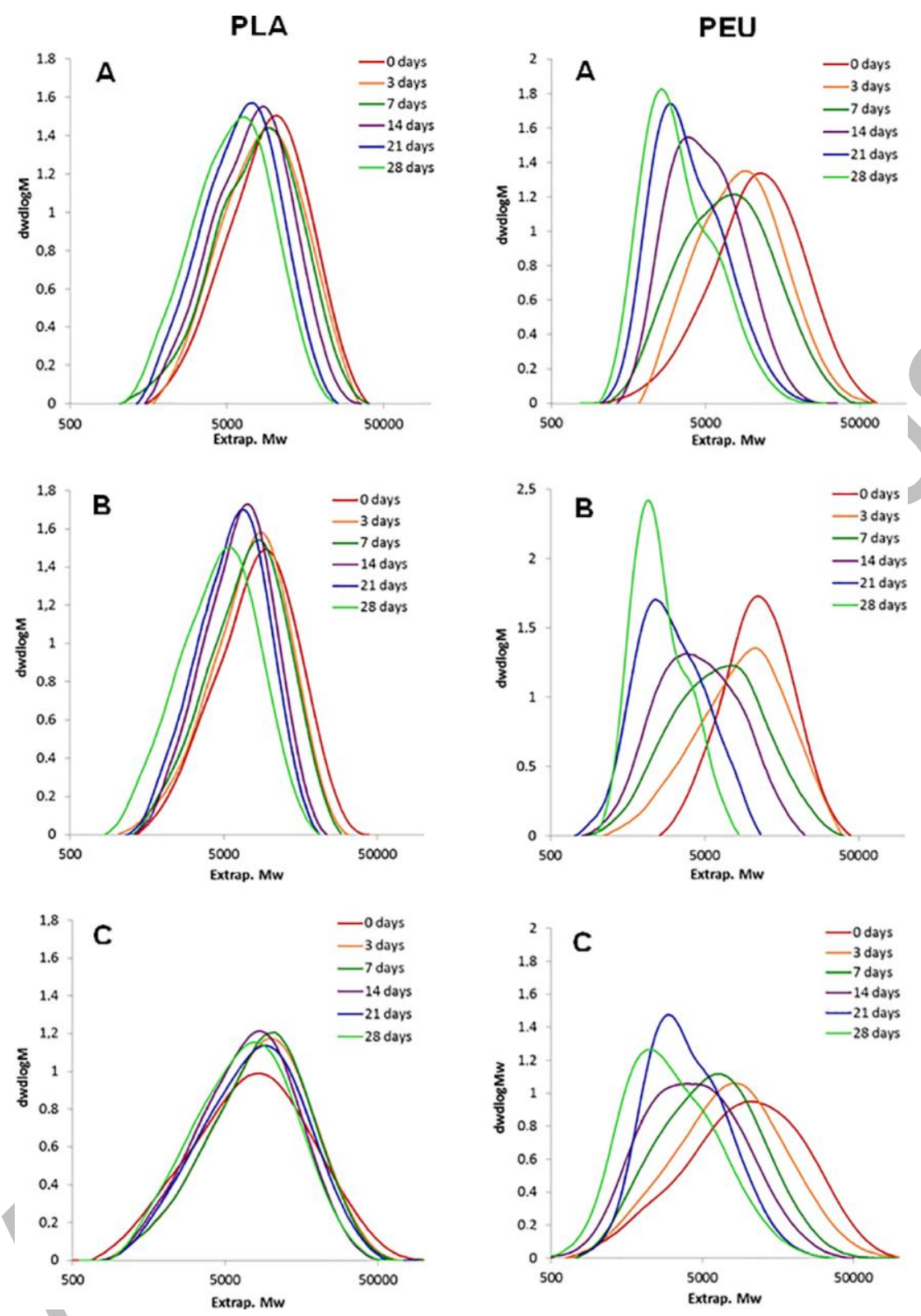
Figure 10. Abiotic hydrolysis experiment of thin layers of untreated and plasma-treated polylactic acid (PLA) and polyester urethane (PEU) in PBS buffer at $\mathrm{pH}=7.4$. Error bars correspond to twice standard deviation $(n=3)$.

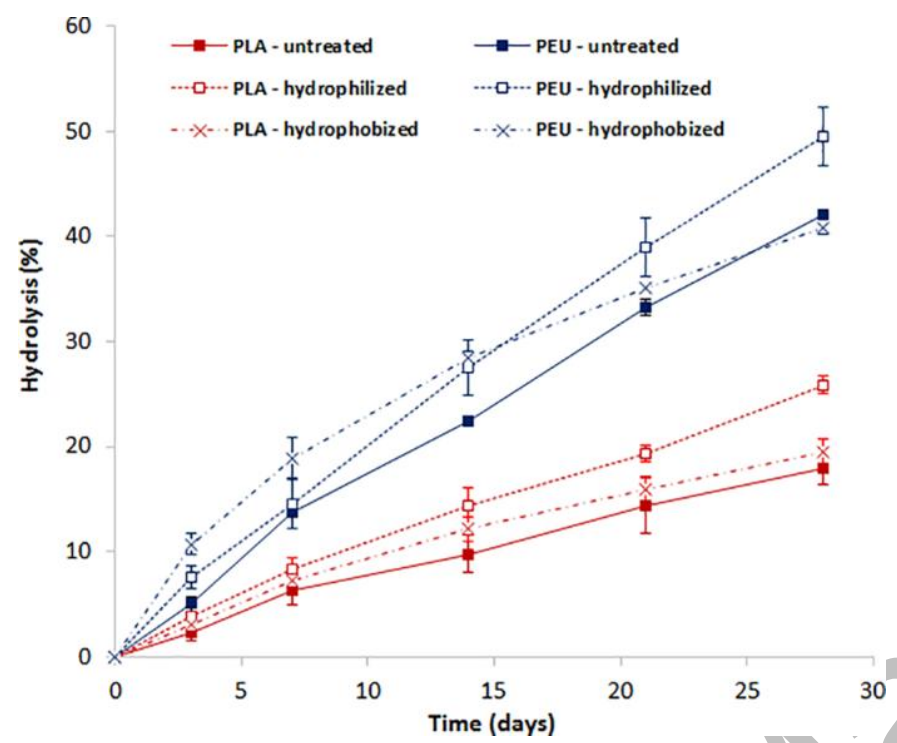


Figure 11. TMZ release profile from thin polylactic acid (PLA) layers in PBS buffer at $\mathrm{pH}=7.4$. The inner graph represents the release profile over the first 24 hours, as fitted with a model according to Equation 4. The error bars correspond to twice standard

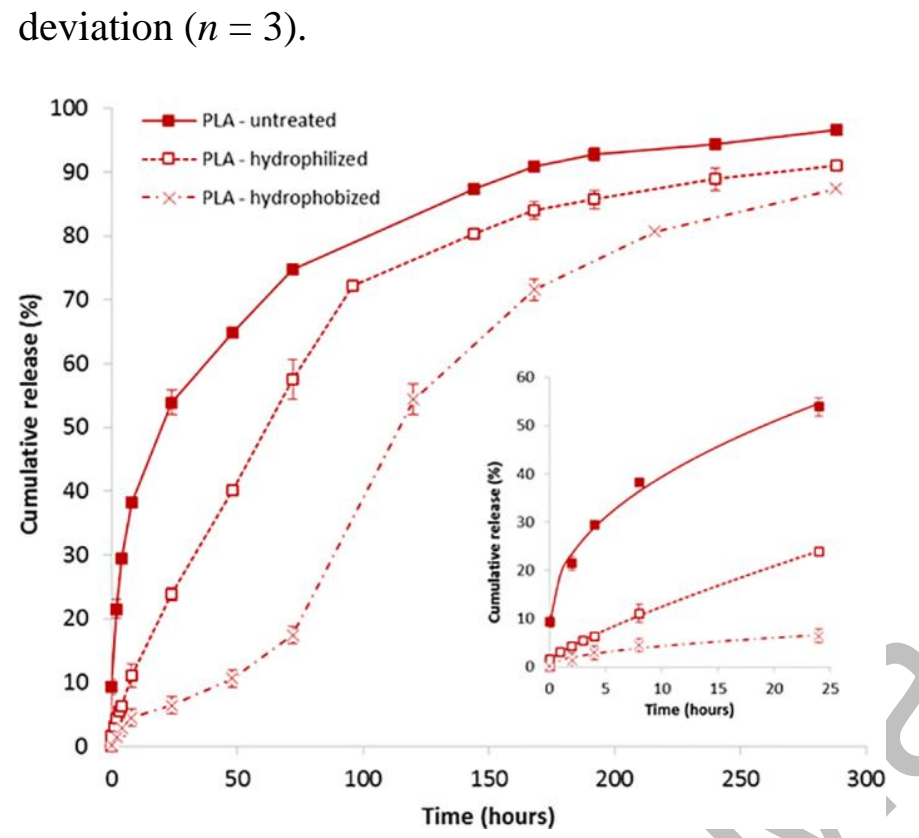


Figure 12. TMZ release profile from thin polyester urethane (PEU) layers in PBS buffer at $\mathrm{pH}=7.4$. The inner graph represents the release profile over first 24 hours, as fitted with a model according to Equation 4. The error bars correspond to twice standard

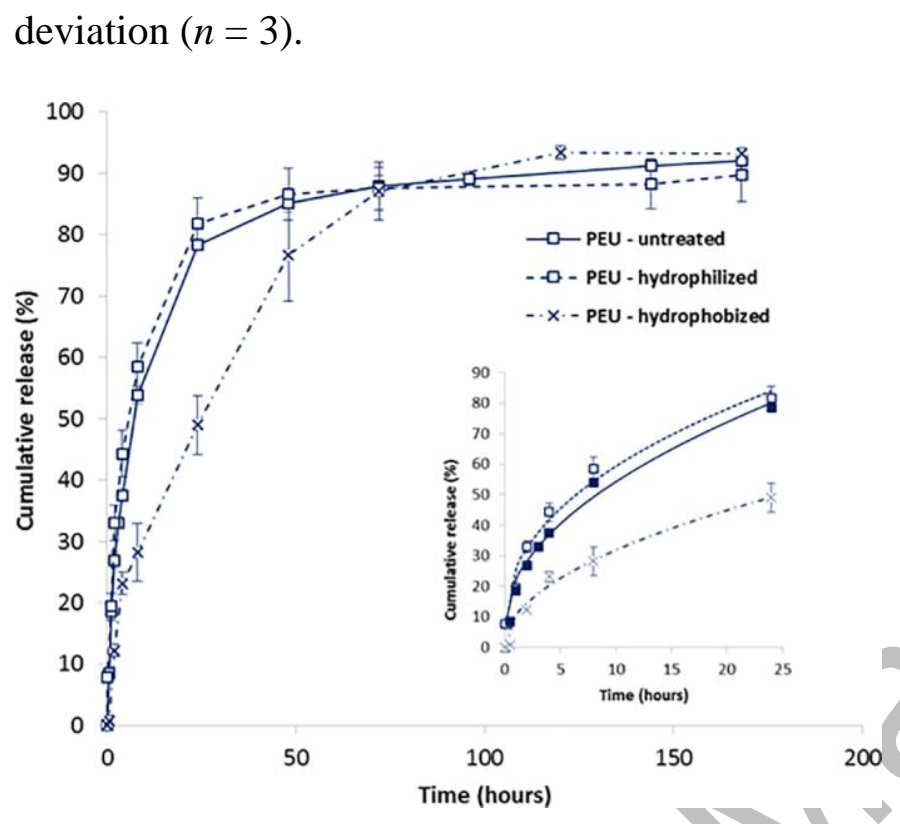

